\title{
Role of single dose antibiotic prophylaxis in prevention of wound infection following lichtenstein inguinal hernioplasty: a randomized clinical trial
}

\author{
KC B, ${ }^{1 *}$ Regmi $R,{ }^{2}$ Agrawal CS, ${ }^{2}$ Pathania $\mathrm{OP}^{2}$ \\ ${ }^{I}$ National Institute of Neurological and Allied Sciences, Kathmandu, Nepal, \\ ${ }^{2}$ BP Koirala Institute of Health Sciences, Dharan, Nepal
}

* Corresponding Author:

Dr Bidur K.C., MS

Department of Neurosurgery

National Institute of Neurological and Allied Sciences,

Bansbari, Kathmandu, Nepal.

Email: kcbidur@gmail.com

\section{Citation}

KC B, Regmi R, Agrawal CS, Pathania OP. Role of single dose antibiotic prophylaxis in prevention of wound infection following lichtenstein inguinal hernioplasty: a randomized clinical trial. Nepal Journal of Medical Sciences 2013;2(2):108-13.

\begin{abstract}
Background: Inguinal hernia is one of commonest condition encountered in clinical practice. Mesh repair is becoming the most popular technique for repair of inguinal hernia. The use of antibiotic prophylaxis for clean surgical procedure such as inguinal hernia surgery is controversial.

Methods: All patients above 18 years of age with primary unilateral inguinal hernia over 14 months period were enrolled. Patients were randomized into 2 groups. Patients with antibiotic prophylaxis group were administered intravenous antibiotic at the induction of anesthesia or just before the incision if operated under local anesthesia (group 1); patients with no antibiotic prophylaxis group were administered sterile normal saline intravenously at the same time (group 2). After Lichtenstein inguinal hernioplasty, patients were followed up twice at 7-9 days and 28-42 days to assess surgical site infection, persistent pain, chronic sinus, testicular atrophy and recurrence if any as final outcome of treatment.
\end{abstract}

Results: Total of sixty patients (59 male and 1 female), thirty in each group were enrolled. During the first follow up, 1 patient (3.3\%) developed wound infection from group 2 where as none of the patients developed wound infection ( $0 \%$ ) from group 1 . During the second follow up, none of the patients from both the groups had any complication.

Conclusion: Inguinal hernia surgery is a clean operation. There is no benefit of intravenous single dose antibiotic prophylaxis in the prevention of wound infection following Lichtenstein inguinal hernioplasty in patients with no other co-morbid conditions.

Keywords: Antibiotic prophylaxis; inguinal hernia; lichtenstein repair; wound infection

\section{Background:}

Hernia is a protrusion of viscus or part of a viscus through an abnormal opening in the walls of its containing cavity. Of which inguinal hernia is one of commonest condition
( $75 \%$ of all external abdominal wall hernia) encountered in clinical practice. ${ }^{1}$

Of the various method for adult inguinal hernia repair, mesh repair is rapidly becoming the most popular technique. ${ }^{2-7} \mathrm{Of}$ 
the open mesh repair technique, Lichtenstein hernia repair is the most frequently performed. The Lichtenstein technique is a tension free repair of weakened inguinal floor using a polypropylene mesh. ${ }^{8}$ Reported rates of wound infection following inguinal hernia surgery vary from $0 \%-9 \%{ }^{9}$ The low rate of wound infection and the straightforward treatment if they occur at all are the main arguments against routine antibiotic coverage during inguinal hernia surgery. ${ }^{10}$

A Cochrane meta-analysis ${ }^{11}$ in 2003 concluded that 'antibiotic prophylaxis for elective inguinal hernia repair cannot be firmly recommended or discarded and further studies are needed, particularly on the use of mesh repair'.

Since inguinal hernia repair represents one of the most frequently performed surgical procedure, ${ }^{12}$ any improvement in their treatment could have a large medical and economic impact, especially a reduction in number of wound infections. Conversely, discarding the use of antibiotic prophylaxis in inguinal hernia repair could reduce the risks of toxic and allergic side effects, the possible development of bacterial resistance ${ }^{13}$ or super-infection and reduce costs. In view of above consideration, we conducted this study to assess the role of single dose intravenous antibiotic prophylaxis over no antibiotic prophylaxis in the prevention of wound infection following Lichtenstein tension free inguinal hernioplasty in patients with no other co-morbid conditions.

\section{Methods:}

A hospital based prospective randomized clinical trial was conducted from April 2008 to June 2009 in the department of surgery at B.P. Koirala institute of health sciences (BPKIHS), Dharan, Nepal. The study was approved by thesis protocol evaluation committee of BPKIHS.

The study included the patients who were above 18 years of age and presented to surgery outpatient department with primary unilateral inguinal hernia. Patients with recurrent or strangulated inguinal hernia, bilateral inguinal hernia or femoral hernia, below 18 years of age, allergic to injection Cefuroxime, with systemic or advanced diseases like diabetes mellitus, liver or renal impairment, patients on steroid or antibiotic within a week before surgery and pregnant or lactating women were excluded from the study.

From all the patients who met inclusion criteria, informed consent was taken to enter into study groups after explaining the procedure in detail. These patients were randomized into 2 groups; intravenous single dose antibiotic prophylaxis group (group 1) and no antibiotic prophylaxis group (group 2). Randomization was done as listed by randomization technique in Microsoft Excel Programme.

All the patients thus selected were evaluated as per predesigned proforma. After detailed history and physical examination routine investigations were sent as required for pre-anesthetic checkup and other investigation were done as required, according to the condition of the patients.

Patients planned under spinal anesthesia were admitted a day before operation where as those who were planned under local anesthesia were carried out as day care operation. Groin of the patient was shaved before operation. The operation was performed either by qualified surgeon with adequate experience or by resident on duty under supervision of faculty.

Patients in group 1 were administered injection Cefuroxime 1.5 Gram with $20 \mathrm{ml}$ of normal saline intravenously at the induction of anesthesia or just before the incision if operated under local anesthesia. Patients in group 2 were administered $20 \mathrm{ml}$ of sterile normal saline intravenously at the same time as mentioned above. Under spinal / local anesthesia, open Lichtenstein inguinal hernioplasty was performed using monofilament polypropylene mesh which was fixed with $2 / 0$ or $3 / 0$ prolene. Operative findings and time was recorded.

For admitted patients immediate post-operative complication like urinary retention, chest infection, venous thrombosis, if any were noted. Wound was inspected on the day of discharge of the patient from the hospital. Patients were discharged from the hospital after satisfactory recovery as assessed by surgeon, usually next day after operation but in patients who were operated on day care basis under local anesthesia were discharged the same day of the operation. Patients were discharge on oral analgesic and oral $\mathrm{H}_{2}$ blocker for 5 days, with advice not to lift heavy weight for 3 months and to follow up after 7-9 days.

Follow up of all the patients were done in 7-9 days and 28-42 days. During first follow up visit detailed history regarding presence or absence of pain over the incision site, redness, local bulging, any discharge from the wound were taken and local examination was done to look for erythema, local bulging, heat, tenderness and any discharge from the wound. Suture was also removed, and patient advised to come on 28-42 days. During second follow up enquiry were made 
regarding presence of persistent pain, presence of persistent of infection, sinus formation, testicular atrophy and for recurrence of hernia.

\section{Wound infection:}

It was defined as following ${ }^{14}$

- Purulent discharge from the incision site, with or without positive culture and sensitivity report

- Non purulent discharge from incision site with positive culture and sensitivity report

- Incision site deliberately opened by surgeon in the presence of at least one of the following signs or symptoms of infection: pain or tenderness, localized swelling, redness or heat.

- Diagnosis of infection by the surgeon

\section{Category of wound infections:}

- Superficial incisional surgical site infection:

Infection occurring within 30 days after surgery involving only skin and/or subcutaneous tissue.

- Deep incisional surgical site infection:

Infection occurring within 1 year after surgery involving fascial, muscle layers and also the mesh.

The collected data were entered into computer using MS Excel programme and analysis were done using software SPSS version 10.

\section{Results:}

Total of sixty patients, thirty in each group were enrolled into the study. Out of 60 patients, there were 59 males and 1 female. Male to female ratio was 59:1. Age ranged from 1990 years and mean age was 38.5 (17.7 SD) years. Maximum numbers of patients were between 19 years to 39 years of age. Duration of illness ranged from 2 month to 22 years with median duration of 2.5 (4.2 SD) years.

Most frequent predisposing factor for hernia was smoking found in 17 patients, 4 patients had chronic constipation, 3 patients had lower urinary tract symptoms and none of them had chronic cough. Hernia was found on right side in 39 patients and on left side in 21 patients. There were 49 indirect and 11 direct type of hernia. 42 patients were operated under local anesthesia where as 18 patients under spinal anesthesia. Surgery duration ranged from 40 minutes to 75 minutes with mean duration of $51.3(9.8 \mathrm{SD})$ minutes.
The baseline characteristics of both groups is shown in table 1 .

Table 1: Showing baseline characteristics of both groups

\begin{tabular}{|c|c|c|c|c|}
\hline $\begin{array}{l}\text { Charac- } \\
\text { teristics }\end{array}$ & & $\begin{array}{c}\text { Antibiotic } \\
\text { prophylaxis } \\
\text { group } n=30\end{array}$ & $\begin{array}{c}\text { No } \\
\text { antibiotic } \\
\text { prophylaxis } \\
\text { group } n=30\end{array}$ & $\begin{array}{l}\text { Total } \\
n=60\end{array}$ \\
\hline \multirow{2}{*}{$\begin{array}{l}\text { Age in } \\
\text { years }\end{array}$} & $<30$ & $12(40 \%)$ & $11(36.7 \%)$ & $23(38.3 \%)$ \\
\hline & $\geq 30$ & $18(60 \%)$ & $19(63.3)$ & $37(61.7 \%)$ \\
\hline \multirow{2}{*}{$\begin{array}{l}\text { Sex } \\
\text { distribution }\end{array}$} & Males & $30(100 \%)$ & $29(96.7 \%)$ & $59(98.3 \%)$ \\
\hline & Female & $0(0 \%)$ & $1(3.3 \%)$ & $1(1.7 \%)$ \\
\hline \multirow{3}{*}{$\begin{array}{l}\text { Duration of } \\
\text { illness in } \\
\text { years }\end{array}$} & $<1$ & $13(43.3 \%)$ & $11(36.7 \%)$ & $24(40 \%)$ \\
\hline & $\geq 1$ & $17(56.7 \%)$ & $19(63.3 \%)$ & $36(60 \%)$ \\
\hline & Smoking & $10(33.3 \%)$ & $7(23.3 \%)$ & $17(28 \%)$ \\
\hline $\begin{array}{l}\text { Predis- } \\
\text { posing } \\
\text { factors }\end{array}$ & $\begin{array}{c}\text { Increased } \\
\text { intra- } \\
\text { abdominal } \\
\text { pressure }\end{array}$ & $4(13.3 \%)$ & $3(10 \%)$ & $7(12 \%)$ \\
\hline $\begin{array}{l}\text { Duration of } \\
\text { surgery in } \\
\text { minutes }\end{array}$ & $<50$ & $19(63.3 \%)$ & $15(50 \%)$ & $34(56.7 \%)$ \\
\hline
\end{tabular}

\section{Post-operative complications during hospital stay:}

Out of 18 patients who were operated under spinal anesthesia, 2 patients (11\%) developed urinary retention in immediate post operative period at ward and Foley catheterization was done under aseptic measure but none of these patients developed local wound complications like bruising, hematoma or systemic complication like chest infection, deep vein thrombosis during hospital stay.

\section{Treatment outcome at first follow up at 7-9 days:}

Out of 60 patients in this study 30 in each group, total of 2 patient had tenderness at the incision site, 1 patient from group 2 had non purulent discharge from the wound, pain and tenderness at the wound site so the patient was diagnosed to have superficial wound infection and suture were opened, collection drained and sent for Gram stain and culture sensitivity. Patient was advised for oral antibiotic (Tablet Cefuroxime) for 5 days, daily dressing and to review with reports but on follow up, both Gram stain and culture showed no bacteria, wound was healthy and no erythema or wound discharge seen. One patient (3.33\%) had 
superficial wound infection from group 2 with $\mathrm{P}$ value= 0.365 , which is statistically not significant (Table 2 ).

Table 2: Complication at first follow up

\begin{tabular}{|c|c|c|c|c|}
\hline $\begin{array}{l}\text { Compli- } \\
\text { cations }\end{array}$ & $\begin{array}{c}\text { Antibiotic } \\
\text { prophylaxis } \\
\text { group } n=30\end{array}$ & $\begin{array}{c}\text { No antibiotic } \\
\text { prophylaxis } \\
\text { group } n=30\end{array}$ & $\begin{array}{l}\text { Total } \\
n=60\end{array}$ & P-value \\
\hline Tenderness & $1(3.33 \%)$ & $1(3.33 \%)$ & $2(3.33 \%)$ & \\
\hline $\begin{array}{l}\text { Erythema \& } \\
\text { discharge }\end{array}$ & $0(0 \%)$ & $1(3.33 \%)$ & $1(1.66 \%)$ & 0.365 \\
\hline $\begin{array}{l}\text { Wound } \\
\text { infection }\end{array}$ & $0(0 \%)$ & $1(3.33 \%)$ & $1(1.66 \%)$ & \\
\hline
\end{tabular}

Treatment outcome at second follow up at 28-42 days:

There were total of 60 patients 30 in each group, none of the patients from both groups had persistence of pain, persistent infection, sinus formation, testicular atrophy or recurrence of hernia. One patient from no antibiotic prophylaxis group who had wound infection during first follow up was also fine as there were no persistence of infection.

\section{Discussion:}

Inguinal hernia is the commonest problem amongst all external hernias and surgery for inguinal hernia is one of the most common procedures performed in a general surgical service, accounting for approximately one-third of all interventions. ${ }^{15}$ Although many patients are asymptomatic, most of them have local symptoms and if left untreated, hernia itself has potential complications such as irreducibility, incarceration, strangulation, peritonitis and sepsis. ${ }^{16}$ Mesh repair is accepted as a gold standard in inguinal hernia repair worldwide. ${ }^{6,17,18}$ Of open mesh repair Lichtenstein “open flat mesh repair" is the most popular., ${ }^{2,45,12}$

There is also no doubt that antibiotic prophylaxis is needed in selected 'clean' surgical procedure where prosthesis is implanted, because the consequences of graft infection can be severe or even fatal. ${ }^{19,20}$ However the benefit of antibiotic prophylaxis in other 'clean' surgical procedure, such as inguinal hernia surgery, has been considered questionable. The low rate of wound infection and the straightforward treatment if they occur at all are the main arguments against routine antibiotic coverage during inguinal hernia surgery. ${ }^{10}$

Since inguinal hernia repair represents one of the most frequently performed surgical procedure ${ }^{12}$ any improvement in their treatment could have a large medical and economic impact, especially a reduction in number of wound infections. Conversely, discarding the use of antibiotic prophylaxis could reduce the risks of toxic and allergic side effects, the possible development of bacterial resistance ${ }^{13}$ or super-infection and reduce costs.

Although age incidence is distributed in all decades of life, in this study we had included patients above 18 years of age. Age distribution ranged from 19 years to 90 years with Mean age of 38.53 years (17.6 SD); majority of the patients $23(38.3 \%)$ were between 19-29 years of age followed by 18 $(30 \%)$ who were 50 years of age. Aufenacker ${ }^{21}$ et al in a study of 1008 patients had mean age 58.25 years (13.1SD). The mean age of the patients included in a study by Tzovaras et $\mathrm{al}^{22}$ was 63 years ranged from 15 years to 90 years. Taylor et $\mathrm{al}^{23}$ found mean age of 56.6 years (16.9) out of 563 patients. Mean age was lower in this study, could be because most of patients $(70 \%)$ were operated in day care operation theatre under local anesthesia. there were 59 males $(98.3 \%)$ and 1 female $(1.7 \%)$ patient. It is comparable to the study done by Aufenacker et $\mathrm{al}^{21}$ where there were 971 males $(96.3 \%)$ and 37 female $(3.7 \%)$ patients, Taylor et $\mathrm{al}^{23}$ where there were 533 males $(95 \%)$ and 30 females $(5 \%)$ patients.

Inguinal hernia is more common on the right side, in adult male $55 \%$ are right sided. ${ }^{1}$ In our study, 39 patients $(65 \%)$ had right sided where as 21 patients $(35 \%)$ had left sided inguinal hernia. Ul Haq et el ${ }^{24}$ in study of 100 patients found 47 patients (47\%) had right sided, 29 patients (29\%) had left sided and 24 patients (24\%) had bilateral inguinal hernia. Any condition which raises intra-abdominal pressure, such as a powerful muscular effort, may produce hernia. Hernias are more common amongst smoker, which may be a result of acquired collagen deficiency. ${ }^{1}$ In this study, there were 17 smoker $(28.3 \%), 4$ patients $(6.7 \%)$ had chronic constipation, 3 patients $(5 \%)$ had straining at micturation but no patients had chronic cough. In our study, 42 patients (70\%) had hernioplasty under local anesthesia and 18 patients (30\%) under spinal anesthesia. It is comparable to study done by Tzovarus et $\mathrm{al}^{22}$ who operated 329 patients (86\%) under local anesthesia, 50 patients (14\%) under regional or general anesthesia. In adult males, $65 \%$ of inguinal hernias are indirect hernia. ${ }^{1}$ Out of 60 patients in this study we had found 49 patients $(82 \%)$ with indirect hernia and 11 patients $(18 \%)$ with direct hernia. Which is higher than the study done by Tzovarus et $\mathrm{al}^{22}$ who reported indirect hernia in 221 patients (58\%) and direct hernia in 158 patients (42\%) and Aufenacker et $\mathrm{al}^{21}$ who found indirect hernia in 454 patients $(45 \%)$, direct hernia in 406 patients $(40 \%)$ and combined in 148 patients $(15 \%)$. In our study, cause for higher recording of indirect hernia could be, $70 \%$ of the patients underwent hernioplasty in day care operation theatre on ambulatory basis because we tend to choose young and healthy adult patients. 
Duration of surgery ranged from 40 minutes to 75 minutes with mean duration of 51.33 minutes (9.78SD). Majority of the patients $68 \%$ were operated between 40 minutes to 50 minutes. It is comparable to study done by Perez et $\mathrm{al}^{25}$ who found mean duration of surgery was 53 minutes. It is lower than the study done by Yerdel et $\mathrm{al}^{26}$ who reported mean duration of 63 minutes but it is higher than the study of Aufenacker et $\mathrm{al}^{21}$ who showed mean duration of 40 minutes. During postoperative period out of 18 patients who were operated under spinal anesthesia 2 patients (11\%) had developed urinary retention in our study. Ul Haq et $\mathrm{al}^{24}$ in his study found urinary retention in 2 patients $(2 \%)$ out of 100 patients. Higher rate of retention could be because we included only 18 patients (30\%) under spinal anesthesia.

During the first follow up, out of 60 patients (3o in each group), 1 patient (3.3\%) developed wound infection from the no antibiotic prophylaxis group where as none of the patients developed wound infection $(0 \%)$ from the antibiotic prophylaxis group. It is comparable to study done by Ul Haq et $\mathrm{al}^{24}$ who reported 3 patient $(3 \%)$ with wound infection in 100 patients without antibiotic prophylaxis. In the literature variable rates of wound infection have been reported like, Aufenacker et $\mathrm{al}^{21}$ found 9 of 505 patients (1.8\%) with wound infection in placebo group and 8 of 503 patients (1.6\%) with wound infection in antibiotic prophylaxis group, Yerdel et $\mathrm{al}^{26}$ found 12 of 133 patients (9\%) in placebo group and 1 of 136 patients $(0.7 \%)$ with wound infection in antibiotic group, Perez et $\mathrm{al}^{25}$ reported 7 of 180 patients $(3.9 \%)$ in placebo group and 4 of 180 patients $(2.2 \%)$ with wound infection in antibiotic group. In contrast to all the above study Oteiza et $\mathrm{al}^{27}$ reported no wound infection $(0 \%)$ out of 123 patient in placebo group and 1 patient $(0.8 \%)$ with wound infection out of 124 patients in antibiotic prophylaxis group.

During the second follow up, out of 60 patients 30 in each group, none of the patients from both the groups had any complication. 1 patient from the no antibiotic prophylaxis group who had wound infection during first follow up was also fine as there were no persistence of infection. Reason for absence of complications could be because of small sample size and short follow up.

\section{Conclusion:}

There is no benefit of intravenous single dose antibiotic prophylaxis in the prevention of wound infection following Lichtenstein tension free inguinal hernioplasty in patients with no other co-morbid conditions. Since the sample size was small and the follow up period was also short in our study, larger studies with longer period are recommended.

\section{Conflict of Interest: None}

\section{References:}

1. Russel RCG, Williams NS, Bulstrode CJK. Bailey $\&$ love's short practice of surgery, 24th ed. London: Hodder Arnold, 2004: 1272-93.

2. Bay-Nielsen M, Kehlet M, Strand L, et al. Quality assessment of 26304 herniorrhaphies in Denmark: a prospective nationwide study. Lancet 2001;358:1124 8 .

3. Hair A, Duffy K, McLean J, et al. Groin hernia repair in Scotland. Br J Surg 2000;87:1722-6.

4. Nilsson E, Haapaniemi S, Gruber G, et al. Methods of repair and risk for reoperation in Swedish hernia surgery from 1992 to 1996. Br J Surg 1998;85:168691.

5. Nyhus LM, Alani A, O’Dwyer PJ, et al. The problem: how to treat a hernia. In: Schumpelick V, Nyhus LM, eds. Meshes: Benefits and Risks, 1st ed. Berlin: Springer-Verlag, 2004:3-30.

6. Grant A. Mesh compared with non-mesh methods of open groin hernia repair: systematic review of randomized controlled trials. Br J Surg 2000;87:854 9.

7. Grant A. Repair of groin hernia with synthetic mesh: meta-analysis of randomized controlled trials. Ann Surg 2002;235:322-32.

8. Lichtenstein IL, Shulman AG, Amid PK, et al. The tension-free hernioplasty. Am J Surg 1989;157:18893.

9. Stephenson BM. Complications of open groin hernia repair. Surg Clin North Am 2003;83:1255-78.

10. Glassow F. Is postoperative wound infection following simple inguinal herniorraphy a predisposing cause for recurrent hernia? Can J Surg 1964;91:870-1.

11. Sanchez-Manuel FJ, Seco-Gil JL. Antibiotic prophylaxis for hernia repair. Cochrane Database Syst Rev 2003; 2:CD003769.

12. Rutkow IM. Demographic and socioeconomic aspects of hernia repair in the United States in 2003. Surg Clin North Am 2003;83:1045-51.

13. Waldvogel FA, Vaudaux PE, Pittet D, et al. Perioperative antibiotic prophylaxis of wound and 
foreign body infections: microbial factors affecting efficacy. Rev Infect Dis 1991;13:782-9.

14. Horan TC, Gaynes RP, Martone WJ, et al. CDC definitions of nasocomial surgical site infections, 1992: a modification of CDC definitions of surgical wound infections. Infect Control Hosp Epidemiol 1992;13:606-8.

15. Devereux DF, O'Connell SM, Liesch JB, et al. Induction of leukocyte activation by meshes surgically implanted in the peritoneal cavity. Am J Surg 1991;162:243-6.

16. Sanabria A, Dominguez L, Valdivieso E, et al. Prophylactic antibiotics for mesh inguinal hernioplasty. A meta-analysis. Ann Surg 2007;245:392-6.

17. Cainzos M, Lozano F, Balibrea JL. Postoperative infection: multicentric, prospective and controlled study. Cir Esp 1990;48:481-90.

18. Wrijland WW, van den Tol MP, Luijendijk RW, et al. Randomized clinical trial of non-mesh versus mesh repair of primary inguinal hernia. Br J Surg 2002;89:293-7.

19. Hill C, Flamant R, Mazas F, et al. Prophylactic cefazolin versus placebo in total hip replacement. Lancet 1981;1:795-6.

20. Kaiser AB, Petracek MR, Lea JV, et al. Efficacy of cefazolin, cefamandole and gentamicin as prophylactic agents in cardiac surgery: results of a prospective, randomized, double-blind trial in 1,030 patients. Ann Surg 1987;206:791-7.

21. Aufenacker TJ, van Geldere D, van Mesdag T, et al. The role of antibiotic prophylaxis in prevention of wound infection after Lichtenstein open mesh repair of primary inguinal hernia: a multicenter double-blind randomized controlled trial. Ann Surg 2004;240:955-60.

22. Tzovaras G, Delikoukos S, Christodoulides G, et al. The role of antibiotic prophylaxis in elective tensionfree mesh inguinal hernia repair: result of a single centre prospective randomized trial. Int J Clin Pract 2007;61:236-9.

23. Taylor EW, Byrne DJ, Leaper DJ, et al. Antibiotic prophylaxis and open groin hernia repair. World J Surg. 1997;21:811-5.

24. Ul Haq RN, Chaudhary IA, Khan BA, et al. Groin sepsis following Lichtenstein inguinal hernioplasty without antibiotics prophylaxis: A review of 100 cases. Pak J Med Sci 2006;22:416-9.

25. Perez AR, Roxas MF, Hilvano SS. A randomized, double-blind, placebo-controlled trial to determine effectiveness of antibiotic prophylaxis for tension-free mesh herniorrhaphy. J Am Coll Surg 2005;200:3938 .

26. Yerdel MA, Akin EB, Dolalan S, et al. Effect of singledose prophylactic ampicillin and sulbactam on wound infection after tension-free inguinal hernia repair with polypropylene mesh: the randomized, doubleblind, prospective trial. Ann Surg 2001;233:26-33.

27. Otezia F, Ciga MA, Ortiz H. Antibiotic prophylaxis in inguinal hernioplasty. Cir Esp 2004;75:69-71. 